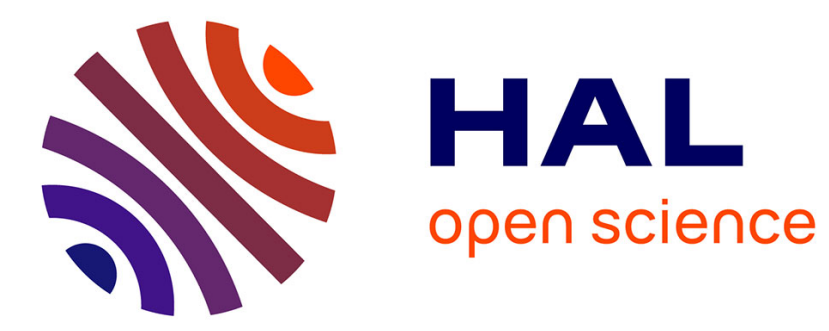

\title{
On the Critical Nominal Strain in Adiabatic Shear Banding
}

\author{
J. Minot, C. Fressengeas
}

\section{To cite this version:}

J. Minot, C. Fressengeas. On the Critical Nominal Strain in Adiabatic Shear Banding. Journal de Physique IV Proceedings, 1997, 07 (C3), pp.C3-785-C3-790. 10.1051/jp4:19973133 . jpa-00255420

\section{HAL Id: jpa-00255420 https://hal.science/jpa-00255420}

Submitted on 1 Jan 1997

HAL is a multi-disciplinary open access archive for the deposit and dissemination of scientific research documents, whether they are published or not. The documents may come from teaching and research institutions in France or abroad, or from public or private research centers.
L'archive ouverte pluridisciplinaire HAL, est destinée au dépôt et à la diffusion de documents scientifiques de niveau recherche, publiés ou non, émanant des établissements d'enseignement et de recherche français ou étrangers, des laboratoires publics ou privés. 


\title{
On the Critical Nominal Strain in Adiabatic Shear Banding
}

\author{
J.L. Minot and C. Fressengeas \\ Laboratoire de Physique et Mécanique des Matériaux, URA $N^{\circ} 1215$ du CNRS, Université de Metz, \\ B.P. 80794, Ile du Saulcy, 57012 Metz cedex 01, France
}

\begin{abstract}
The attention is focused on the influence of boundary conditions on the critical nominal strain to failure in adiabatic shear banding. First, the influence of mixed velocity-stress conditions for a Knowles constitutive law is investigated, then stress controlled and velocity controlled conditions are discussed for a multiplicative power law form. It is shown with an analytical/numerical method that the critical strain is not sensitive to the boundary condition when a Knowles constitutive relation is used, but that it is less under stress controlled conditions than for velocity boundary conditions, when a multiplicative form of the thermoviscoplastic constitutive law is employed.

Résumé. On s'intéresse à l'influence de conditions aux limites sur la déformation nominale critique à rupture en cisaillement adiabatique. Dans un premier temps, l'influence des conditions de chargement mixtes pour la fonction de Knowles est étudiée, ensuite les contrôles en vitesse et en contrainte sont discutés pour une loi puissance multiplicative. Il est montré avec une méthode analytique/numérique que la contrainte critique est insensible aux conditions aux limites quand une loi de comportement de Knowles est utilisée, mais qu'elle est plus faible sous un contrôle en vitesse que sous un contrôle en contrainte lorsque une forme multiplicative de la loi thermoviscoplastique est employée.
\end{abstract}

\section{INTRODUCTION.}

Thermomechanical coupling and thermal softening are at the origin of the localization of plastic flow into Adiabatic Shear Bands (ASBs). It is well known that the onset of the localization process can be traced back without ambiguity to the maximum in the shear stress $\tau$ vs. shear strain $\gamma$ diagram. However a significant scatter in the critical nominal shear strain to failure is observed under constant material conditions. A part of this scatter can be ascribed to the lack of control of the materiel imperfections [1]. In the present paper, the influence of the boundary conditions on the critical shear strain is investigated.

\section{MODEL FORMULATION.}

Let us consider a slab of material of half height $h$ along the $(O, x)$ axis, of infinite extension along $(O, z)$, and of width $l(x)$ in the direction $(O, y)$ (Figure 1.a). The slab is subject to simple shear parallel to $(O, z)$. It is assumed that the only non-zero particle velocity component is $v$ along the $(O, z)$ axis (Figure $1 . b)$; in addition, one assumes that every quantity depends on the abscissa $\mathrm{x}$ and on the time $t$ only. The problem thus defined is $1 \mathrm{D}$; it is designed to model the torsion of a thin walled tubular specimen in the torsional Kolsky bar experiment. Inertial effects being neglected, the shear force does not depend on $\mathrm{x}$, and the equilibrium equation reads

$$
\forall \mathrm{x} \in[-\mathrm{h},+\mathrm{h}] \quad \tau(\mathrm{x}, \mathrm{t}) \mathrm{l}(\mathrm{x})=\tau(0, \mathrm{t}) \mathrm{l}(0)
$$




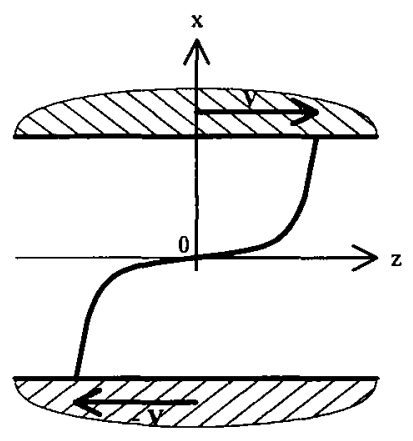

a) Velocity

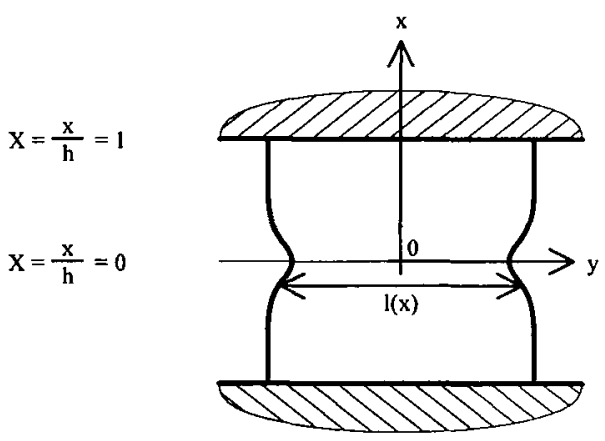

b) Geometrical defect

Figure 1 : Profile of velocity and defect

The material behavior is assumed to be thermoviscoplastic, and the flow stress is taken to be of the general form

$$
\tau=\mu(x) F(\gamma, \theta) \dot{\gamma}^{m}
$$

where $m$ is the strain rate sensivity parameter. The shear modulus is assumed to be $x$-dependent in order to account for a material inhomogeneity or a metallurgical defect. The coefficients used in the Knowles constitutive law

$$
\mathrm{F}(\gamma, \theta)=f(\gamma)=\gamma\left(1+\frac{\mathrm{b}}{\mathrm{n}} \gamma^{2}\right)^{\mathrm{n}-1}
$$

were identified by [2] for the HY-100 steel $(b=8000, n \cong 0.49)$. For the multiplicative power law form of the function $F(\gamma, \theta(\gamma))$

$$
\mathrm{F}(\gamma, \theta)=\theta^{v} \gamma^{n}
$$

the material parameters ( $\mathrm{n}$ the hardening coefficient, $\mathrm{v}$ the thermal softening parameter and $\mathrm{m}$ ) were also identified in [2] for the CRS 1018 steel $(v=-0.38 ; n=0.015 ; m=0.019)$. Under the assumed adiabatic conditions, the energy conservation law is written as

$$
\rho \mathrm{c} \frac{\partial \theta}{\partial \mathrm{t}}=\beta \tau \dot{\gamma}
$$

where $\rho$ denotes the mass density, $c$ the massic thermal capacity, $\theta$ the temperature, $\dot{\gamma}=\frac{\partial v}{\partial x}$ the local strain rate, $\beta$ the Taylor-Quinney coupling constant, the value of which is roughly $\beta \cong 0.9$. Using the relations(2) and (4) allows the integration of the energy equation (5) for either stress controlled : $\tau(h, t)=\tau_{0}$, or velocity controlled boundary conditions $: \mathrm{v}(\mathrm{h}, \mathrm{t})=\mathrm{v}_{0}$

The temperature $\theta$ is then obtained as a function of the plastic deformation $\gamma$ and of the initial temperature $\theta_{0}$. Substituting $\theta(\gamma)$ in (4) leads respectively to :

$$
\mathrm{F}(\gamma, \theta(\gamma))=\mathrm{f}(\gamma)=\theta_{0}{ }^{v}\left(1+\mathrm{a}_{\mathrm{c}} \gamma\right)^{v} \gamma^{\mathrm{n}} \text { with } \mathrm{a}_{\mathrm{c}}=\frac{\beta \tau(\mathrm{x})}{\rho \mathrm{c} \theta_{0}}
$$

for stress controlled boundaries and

$$
\mathrm{F}(\gamma, \theta(\gamma))=\mathrm{f}(\gamma)=\theta_{0}{ }^{\nu}\left(1+\mathrm{a}_{v} \gamma^{n+1}\right)^{\frac{v}{1-\nu}} \gamma^{\mathrm{n}} \text { with } \mathrm{a}_{v}=\frac{\mu(\mathrm{x}) \beta}{\rho \mathrm{c}} \frac{(1-v)}{(1+\mathrm{n})} \frac{\dot{\gamma}_{0}^{\mathrm{m}}}{\theta_{0}^{1-\nu}}
$$

under velocity conditions. The inequalities $n<1 / 2$ for the Knowles function and $v+n<0$ for the multiplicative form indicate that a maximum in the shear stress occurs, beyond which softening is predominant.

Using $f(\gamma)$ as defined by (3), (6) or (7) in (2) and substituting the shear stress $\tau$ in the equilibrium equation (1) leads, after integration, to the localization equation : 


$$
\forall \mathrm{x} \in[-\mathrm{h},+\mathrm{h}] \quad(\mathrm{l}(\mathrm{x}) \mu(\mathrm{x}))^{\frac{1}{m}} \int_{\gamma_{0}}^{(x)} \mathrm{f}(\xi)^{\frac{1}{m}} \mathrm{~d} \xi=(1(0) \mu(0))^{\frac{1}{m}} \int_{\gamma_{0}}^{(0)} \mathrm{f}(\xi)^{\frac{1}{m}} \mathrm{~d} \xi
$$

where the initial plastic deformation $\gamma_{0}$ is supposed to be uniform. Asymptotic $\mathrm{L}_{\infty}$ localization of the plastic deformation occurs in the cross-section $\mathrm{x}=0$ if the deformation becomes unbounded for $\mathrm{x}=0$, while remaining finite for every other $x$ [3] Therefore an asymptotic $L_{\infty}$ localization criterion is obtained by writing that the r.h.s. integral in (8) exists when $\gamma(0)$ becomes unbounded :

$$
\int_{\gamma_{0}}^{\infty} f(\xi)^{\frac{1}{m}} d \xi<\infty
$$

It is respectively, for $f(\xi)$ defined by (3), (6) and (7) :

$$
\begin{array}{cc}
2 n+m-1<0 & \text { (Knowles) } \\
v+n+m<0 & \text { (stress controlled boundaries) } \\
v+n+m(1-v)<0 & \text { (velocity controlled conditions) }
\end{array}
$$

Assuming that the $\mathrm{L}_{\infty}$ localization criterion (10) is fulfilled, the relation (8) appears to be an implicit integral equation for the unknown $\gamma(\mathrm{x})$. Two different solution procedures can be used : one is based on local asymptotic expansions valid in the neighborhood of the defect, the other is an exact analytical solution obtained by means of convergent series developments of the integrals involved in eq. (8). These developments are written in terms of the hypergeometric function ${ }_{2} F_{1}$. The sample geometry and the material non uniformity are specified by the local developments (11) and (13). The sample shear modulus $\mu(x)$ in a neighborhood of the defect is given by the local development :

$$
\forall \mathrm{x} \in\left[-\mathrm{x}_{1},+\mathrm{x}_{1}\right] \quad \mu(\mathrm{x})=\mu(0)+\mu_{\mathrm{r}}(0)|\mathrm{x}|^{\mathrm{r}}
$$

where $r$ represents the sharpness. When $r$ satisfies $r<1$, sharp defects resulting from a material singularity are described; $r>1$ leads to smoother defects. Outside $\left[-\mathrm{x}_{1},+\mathrm{x}_{1}\right]$ a fifth order polynomial expansion matching the local one takes account of the defects size. The relative defect size is equal to :

$$
\varepsilon=\frac{\mu(h)-\mu(0)}{\mu(h)}
$$

Geometrical defects are described by a similar development, excepted that in this case, the acuteness r must be larger than 1 to avoid two dimensional effects.

$$
\forall \mathrm{x} \in\left[-\mathrm{x}_{1},+\mathrm{x}_{1}\right] \quad \mathrm{I}(\mathrm{x})=\mathrm{l}(0)+\mathrm{l}_{\mathrm{r}}(0)|\mathrm{x}|^{\mathrm{r}}
$$

When the asymptotic $L_{\infty}$ localization criterion is satisfied, the integrals involved in eq. (8) can be calculated by using equivalents valid if the plastic deformations $\gamma(0)$ and $\gamma(\mathrm{x})$ are large enough; these conditions are fulfilled when $x$ is small enough. The first order development of the deformation $\gamma(x)$ then turns out to be of the form

$$
\gamma(\mathrm{x}) \cong \mathrm{ax}^{-p}
$$

If it is now required the nominal shear strain be bounded, the integrability of the local plastic deformation yields :

$$
\int_{0}^{x_{1}} \gamma(x) d x<\infty
$$

This boundedness condition is satisfied if and only if $p<1:$ it is called an asymptotic $L_{\infty, x}$ localization criterion under finite nominal strain. It reads respectively, for (3), (6) and (7) :

$$
\begin{array}{cc}
2 n+m(1+r)-1<0 & \text { (Knowles form) } \\
v+n+m(1+r)<0 & \text { (stress controlled bound } \\
v+n+m(1+r)(1-v)<0 & \text { (velocity controlled cond }
\end{array}
$$

When the $\mathrm{L}_{\infty, \mathrm{x}}$ localization criterion is satisfied, the critical nominal strain is defined equivalently as one of the limits :

$$
\gamma_{c}=\lim _{\gamma(0) \rightarrow \infty} \frac{1}{h} \int_{0}^{h} \gamma(x) d x \text { or } \gamma_{c}=\lim _{\tau \rightarrow 0} \frac{1}{h} \int_{0}^{h} \gamma(x) d x
$$

Using equation (14), the contribution to $\gamma_{c}$ of the localization region can be computed with high accuracy. 


\section{MIXED VELOCITY / STRESS BOUNDARY CONDITION WITH KNOWLES CONSTITUTIVE LAW}

Let us suppose a specimen with a geometric defect (Figure 1.b) submitted to mixed velocity/stress boundary conditions :

$$
\begin{array}{ll}
\text { at } x=0 & v(0, t)=0 \\
\text { at } x=h & v(h, t)-\phi \tau(h, t)=v_{0}-\phi \tau_{0} \Leftrightarrow \tau=\tau_{0}+\frac{1}{\phi}\left(v-v_{0}\right)
\end{array}
$$

where $\phi$ is a negative parameter. When $\phi$ tends to zero or minus infinity, the boundary conditions tend respectively to velocity controlled conditions $\left(v_{0}\right)$ or to stress controlled conditions $\left(\tau_{0}\right)$ (Figure 2.a)

Substituting eq. (2) in eq. (1), the shear strain rate $\dot{\gamma}(x, t)$ as well as the shear stress at the edge of the specimen can be computed as a function of the shear strain at the center of the band $\gamma(0, t)$ and of the shear strain rate $\dot{\gamma}(0, t)$. Thus we obtain the velocity and shear stress at the edge :

$$
\begin{gathered}
\dot{\gamma}(\mathrm{x}, \mathrm{t})=\dot{\gamma}(0, \mathrm{t})\left(\frac{\mathrm{l}(0) \mu(0)}{\mathrm{l}(\mathrm{x}) \mu(\mathrm{x})} \frac{\mathrm{f}(\gamma(0, \mathrm{t}))}{\mathrm{f}(\gamma(\mathrm{x}, \mathrm{t}))}\right)^{\frac{1}{\mathrm{~m}}} ; \mathrm{v}(\mathrm{h}, \mathrm{t})=\int_{0}^{\mathrm{h}} \dot{\gamma}(\mathrm{x}, \mathrm{t}) \mathrm{dx} \\
\tau(\mathrm{h}, \mathrm{t})=\frac{1(0)}{\mathrm{l}(\mathrm{h})} \tau(0, \mathrm{t})=\frac{\mathrm{l}(0)}{\mathrm{l}(\mathrm{h})} \mu(0) \mathrm{f}(\gamma(0, \mathrm{t})) \dot{\gamma}(0, \mathrm{t})^{\mathrm{m}}
\end{gathered}
$$

Using the Knowles form (3) of the function $f(\gamma), \gamma(x, t)$ can be obtained from the computation of the implicit integral equation (8) with only one term of the hypergeometric function ${ }_{2} F_{1}$ for large enough plastic deformation. Substituting (19) and (20) in (18), a differential equation for the unknown $\gamma(0, t)$ is obtained :

$$
\int_{0}^{\mathrm{h}}\left(\frac{\mathrm{l}(0) \mu(0)}{\mathrm{l}(\mathrm{x}) \mu(\mathrm{x})} \frac{\mathrm{f}(\gamma(0, \mathrm{t}))}{\mathrm{f}(\gamma(\mathrm{x}, \mathrm{t}))}\right)^{\frac{1}{\mathrm{~m}}} \mathrm{dx} \dot{\gamma}(0, \mathrm{t})-\phi \frac{\mathrm{l}(0)}{\mathrm{l}(\mathrm{h})} \mu(0) \mathrm{f}(\gamma(0, \mathrm{t})) \dot{\gamma}(0, \mathrm{t})^{\mathrm{m}}=\mathrm{v}_{0}-\phi \tau_{0}
$$

If the shear strain $\gamma(0, t)$ is given, the shear strain rate $\dot{\gamma}(0, t)$ at the center of the band can be computed from eq. (21); then the shear stress $\tau(h, t)$ is obtained from eq. (20) and the nominal shear strain $\gamma_{\text {nom }}(t)$ can be computed. The shear strain at an instant dt later $\gamma(0, \mathrm{t}+\mathrm{dt})$ is obtained by a first order Taylor development. The shear stress-nominal shear strain curve is plotted in Figure 2.b.

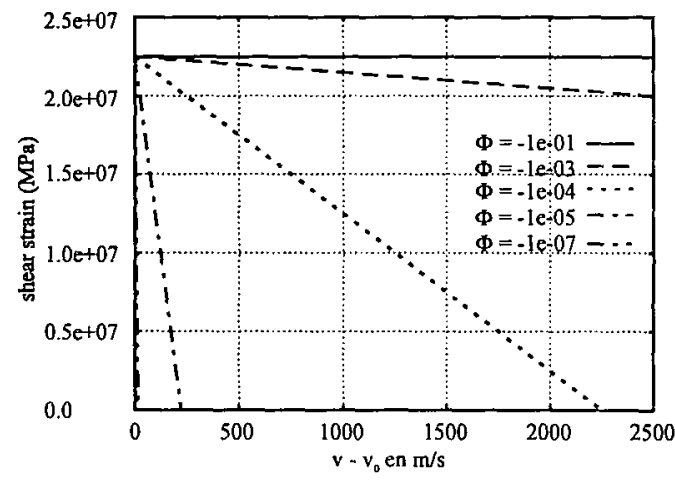

a) Edge shear stress-velocity curves

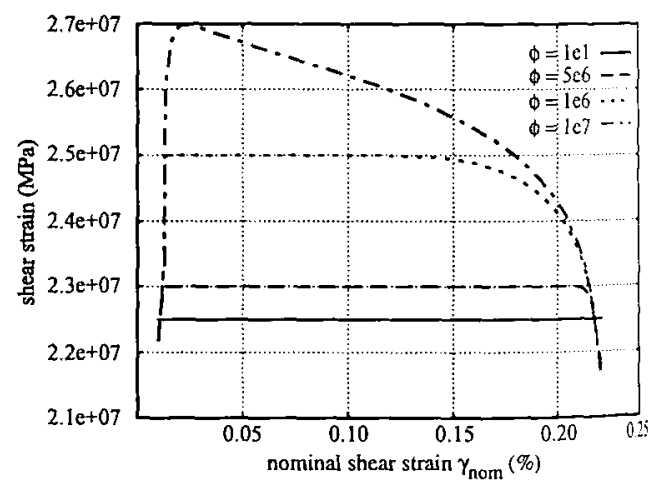

b) shear stress-nominal shear strain curves with different parameter: 0

Figure 2 : Edge shear stress-yelocity curves and shear stress-nominal shear strain curves with different parameters $\phi$

For the material parameters $n=0.49, b=8000, m=0.08$ and loading parameters $\tau_{0}=22.5 \mathrm{Mpa}$ and $\mathrm{v}_{0}=$ $2.5 \mathrm{~ms}^{-1}$, the Figure 2.a shows that the loading conditions are nearly stress controlled for $\phi=-10^{-1}$ and velocity controlled for $\phi=-10^{-7}$. Thus this study does not need an interval larger than $\left[-10^{-1} ;-10^{-7}\right]$. Figure 2.b shows that five curves for different parameters $\phi$ exhibit different stress-strain histories but have the same critical nominal shear strain $\gamma_{c}$, which, therefore, does not to depend on the imposed boundary 
condition. Such a conclusion has been drawn in [4] after finite element calculations with a linearized thermally activated constitutive law of the form :

$$
F(\gamma, \theta(\gamma))=f(\gamma)=e^{v \theta} \gamma^{n}
$$

However this conclusion may depend on the form of the thermoviscoplastic function $F(\gamma, \theta(\gamma))$ used in the formulation. Therefore, a multiplicative form is employed in the next part of this paper.

\section{MULTIPLICATIVE POWER LAW FORM}

With the multiplicative power law form (4), an analytical investigation of mixed velocity/stress conditions is impossible because the function $f(\gamma)$ is different for stress controlled boundaries (6) or velocity controlled conditions (7). To compare the two loading conditions, an imposed shear stress $\tau_{0}$ and a velocity $v_{0}$ must be found such that the two experiments use the same amount of energy during the deformation process:

$$
\mathrm{W}=\int_{0}^{\gamma_{\epsilon}} \tau \mathrm{d} \gamma
$$

Using for instance the material identified by [2], with a material defect $\left(\mu(\mathrm{h})=0.357910^{10} \mathrm{SI}\right.$, $\left.\mu_{r}(0) / \mu(h)=0.04, r=2, \varepsilon=0.04, x_{1} / h=0.2, h=0.0025 \mathrm{~m}\right)$ and submitted to either velocity condition $v_{0}=2,5 \mathrm{~ms}^{-1}$ or stress controlled boundary condition $\tau_{0}=423 \mathrm{MPa}$, a same amount of energy is used in the shear band development. The Figure 3 shows that the critical nominal strains are nearly identical.

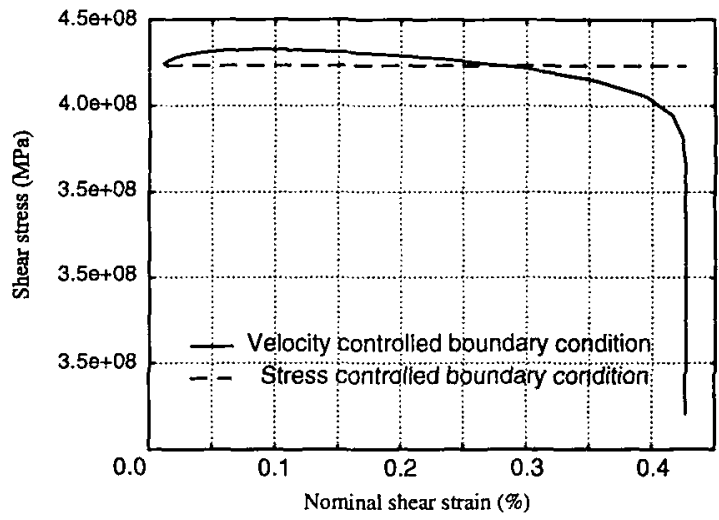

Figure 3 : Shear strain-nominal shear strain curve

We can notice however that the $\mathrm{L}_{\infty, \mathrm{r}}$ localization criteria are different in these two cases (stress controlled boundaries: $v+n+m(1+r)<0$; velocity controlled conditions : $v+n+m(1+r)(1-v)<0)$. Recall that if the criterion is satisfied, the critical nominal strain $\gamma_{c}$ has a finite value, while, if not, $\gamma_{c}$ tends to infinity. For example, if the parameters $n, m$ and $r$ are kept constant, a plot of the critical nominal strain vs. $v$ displays an asymptotic increase either at $v=-n-m(1+r)$ (stress controlled conditions) or at $v=\frac{-n-m(1+r)}{1-m(1+r)}$ (velocity controlled conditions), as shown in Figure 4.a 


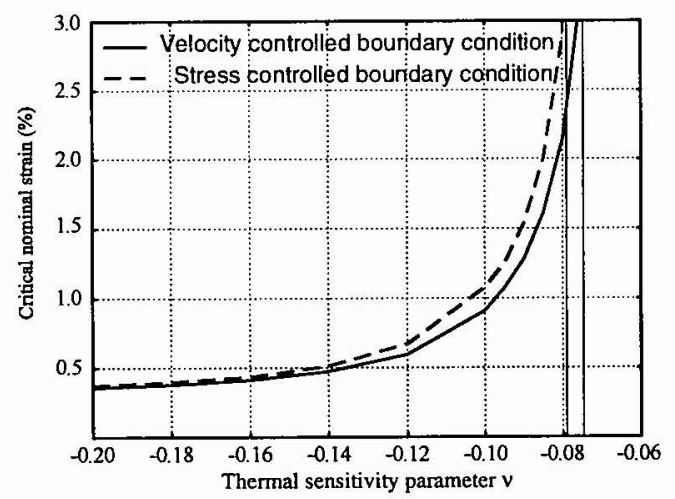

a) Nominal shear strain-parameter $v$ curve with $n=0.015$ and $m=0.019$

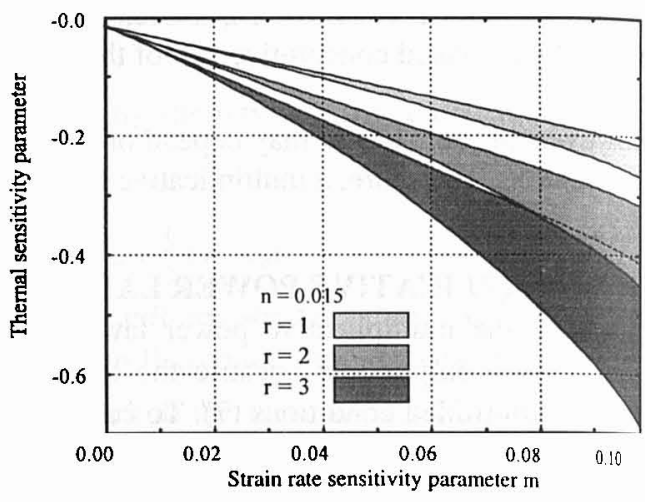

b) Maps showing areas where boundary conditions yield a significant dispersion of the critical shear strain $\gamma_{t}$

Figure 4 : Influence of the boundary conditions on the critical nominal strain

Between these two asymptots,

$$
-\mathrm{n}-\mathrm{m}(1+\mathrm{r})<\mathrm{v}<\frac{-\mathrm{n}-\mathrm{m}(1+\mathrm{r})}{1-\mathrm{m}(1+\mathrm{r})}
$$

$\gamma_{\mathrm{c}}$ has a finite value for the controlled velocity and an infinite value in the other case. Therefore, in this area and close to it, the critical nominal strain necessarily depends on the boundary conditions. For the C.R.S. 1018 steel and the acuteness $r=2$, the parameter $v=-0.38$ is far of this interval and the influence of the loading condition due to the $\mathrm{L}_{\infty_{\mathrm{r}}}$ localization criterion can be neglected. However, in the shaded areas of Figure 4.b, the inequalities (24) are satisfied. In these areas and in their neighborhood, the critical nominal shear strain significantly depends on the loading conditions of the specimen.

\section{CONCLUSION}

By using the thermally activated law (22) or the Knowles hardening/softening function (3), it is found that the critical nominal shear strain does not depend on the boundary conditions applied to the specimen. In addition, it can be shown that the $L_{\infty_{x}}$ criteria are identical in both cases [5], regardless of the boundary conditions that are being used. This is in fact the basic reason why boundary conditions have no influence on the critical shear strain. However, if the material behavior is modeled by a multiplicative power law, boundary conditions may yield significant variations in the critical nominal strain.

Since the control of boundary conditions may prove difficult in most experimental set ups, this result suggests that at least a part of the scatter observed in the critical nominal strain may be ascribed to their unchecked variations.

\section{References}

[1] Dinzart F., Fressengeas C., Molinari A., C.R. Acad. Sci. Paris 319,II (1994) 381-386.

[2] Marchand A. and Duffy J., J. Mech. Phys. Solids, Vol. 1 (1988) 251-283.

[3] Molinari A. and Clifton R.J., J. of Appl. Mech. Vol. $36 \mathrm{n}^{\circ} 3$ (1987) 806-812.

[4] Leroy Y., Bonvalot B., Molinari A., J. Phys IV C8 (1994) 429-434.

[5] Minot J.L., Doctorate thesis, University of Metz (1997). 